\title{
CORRELATION OF PROCALCITONIN LEVEL WITH SEPSIS DEGREES BASED ON SOFA SCORE
}

\author{
Citra Novita, Soeprapto Maat, Betty Agustina Tambunan
}

Department of Clinical Pathology, Faculty of Medicine, Airlangga University/Dr.Soetomo Hospital, Surabaya, Indonesia. E-mail: citra8.nov@gmail.com

\begin{abstract}
Sepsis is defined as a life-threatening organ dysfunction condition caused by dysregulation of host response towards an infection. Sepsis is one of the leading causes of death in a medical emergency. A recent study revealed 18 millions of sepsis occur annually with a mortality rate of $30 \%$, so early diagnosis in assessing sepsis severity is necessary as a guide for early and specific therapy. Organ dysfunction in sepsis patients is associated with high mortality, assessed by Sequential Organ Failure Assessment (SOFA) criteria. Procalcitonin is widely used for diagnosing, monitoring, and prognosis sepsis. This study aimed to analyze the correlation of procalcitonin level with sepsis severity based on SOFA score. This was an observational cross-sectional study. Samples were collected from December 2017-February, 2018 of 72 patients. Each patient was calculated by SOFA score and underwent procalcitonin examination using an immunochromatography method by the RAMP. Samples from 72 patients who met the criteria were analyzed, consisting of 37 males (51.4\%) and 35 females (48.6\%), aged 23-77 years, with mean \pm SD $47.4 \pm 14.02$ years. The range of SOFA score was $0-16$ with mean \pm SD were $6.47 \pm 3.61$, while procalcitonin levels were $0.20-200 \mathrm{ng} / \mathrm{mL}$ with mean \pm SD were $21.03 \pm 14.63 \mathrm{ng} / \mathrm{mL}$. There was a significant correlation between procalcitonin level and SOFA score $(r=0.752 ; p<0.0001)$. This suggests that procalcitonin may illustrate the severity of sepsis patients. The higher the procalcitonin, the more severe the sepsis. SOFA score and procalcitonin examinations should be performed routinely in patients with sepsis to assess prognosis (severity) for earlier pretreatment so that the mortality rate can be lowered.
\end{abstract}

Key words: Procalcitonin level, sepsis severity, SOFA score

\section{INTRODUCTION}

Sepsis is defined as a life-threatening organ dysfunction condition caused by dysregulation of host response towards infection. ${ }^{1-3}$ Sepsis is one of the leading causes of death in a medical emergency despite the use of new antibiotics and further resuscitation therapy. ${ }^{1,4}$ Definition of sepsis previously included Systemic Inflammatory Response Syndrome (SIRS) as the criteria of sepsis in the 1991 consensus. Four criteria of SIRS are tachycardia (heart rate > 90 times/minute), tachypnea (breathing $>20$ times/minute), fever or hypothermia (temperature $>38$ or $<36^{\circ} \mathrm{C}$ ), and leukocytosis, leukopenia, or bandemia (white blood cells $>12,000 / \mathrm{mm}^{3},<4,000 / \mathrm{mm}^{3}$ or bandemia $\geq 10 \%$ ). Patients with two or more of these criteria match the definition of SIRS. Sepsis had other terms such as severe sepsis and septic shock at the time. Sepsis that reaches the stage of organ failure is categorized as severe sepsis, whereas in septic shock, Organ dysfunction occurs with persistent hypotension. ${ }^{2,3,5,6}$ The definition of sepsis was expanded in 2001 that patients must have at least two criteria for SIRS with a proven or suspected infection process. ${ }^{2.3}$

Organ dysfunction in sepsis patients is associated with high mortality and an increase in hospitalization costs. It is assessed using criteria Sequential Organ Failure Assessment (SOFA) that evaluates the severity and organ dysfunction (Table 1). ${ }^{1.4}$ Organ dysfunction can be identified from the total score of the SOFA, which is $\geq 2$ and reflects their mortality risk of approximately $\geq 10 \%$ in the population suspected of infection in hospitals. A higher SOFA score is associated with an increased probability of mortality. The Society of Critical Care Medicine (SCCM) and the European Society of Intensive Care Medicine (ESICM) proposed a new definition of sepsis called sepsis-3 that is quick SOFA (qSOFA). Quick SOFA is based on the existence of two of the three signs of organ dysfunction. These patients have a high risk of death or long treatment in the intensive care unit. The three warning signs included changes in mental status, systolic blood pressure $\leq 100 \mathrm{mmHg}$, and breathing frequency $\geq 22 /$ minute. $^{2,3}$ 
Table 1. Sequential organ failure assessment score ${ }^{1,2,4}$

\begin{tabular}{|c|c|c|c|c|c|}
\hline \multirow{2}{*}{ Organ system } & \multicolumn{5}{|c|}{ SOFA score } \\
\hline & 0 & 1 & 2 & 3 & 4 \\
\hline $\begin{array}{l}\text { Respiratory, } \mathrm{PO}_{2} / \mathrm{FiO}_{2}, \mathrm{mmHg} \\
(\mathrm{kPa})\end{array}$ & $\begin{array}{l}\geq 400 \\
(53.3)\end{array}$ & $\begin{array}{l}<400 \\
(53.3)\end{array}$ & $\begin{array}{l}<300 \\
(40)\end{array}$ & $\begin{array}{c}<200 \\
\text { (26.7) with respiratory } \\
\text { support }\end{array}$ & $\begin{array}{c}<100 \\
(13.3) \text { with respiratory }\end{array}$ \\
\hline Coagulation, Platelets, $\times 10^{3} / \mathrm{mm}^{3}$ & $\geq 150$ & $<150$ & $<100$ & $<50$ & $<20$ \\
\hline Liver, Bilirubin, mg/dL & $<1.2$ & $1.2-1.9$ & $2.0-5.9$ & $6.0-11.9$ & $>12.0$ \\
\hline Cardiovascular & $\begin{array}{c}\text { MAP } \\
\geq 70 \mathrm{mmHg}\end{array}$ & $\begin{array}{c}\text { MAP } \\
<70 \mathrm{mmHg}\end{array}$ & $\begin{array}{c}\text { Dopamine }<5 \text { or } \\
\text { dobutamine } \\
\text { (any dose) })^{\mathrm{b}}\end{array}$ & $\begin{array}{l}\text { Dopamine } 5.1-15 \text { or } \\
\text { epinephrine } \leq 0.1 \text { or } \\
\text { norepinephrine } \leq 0.1^{b}\end{array}$ & $\begin{array}{l}\text { Dopamine }>15 \text { or } \\
\text { epinephrine }>0.1 \text { or } \\
\text { norepinephrine }>0.1^{\circ}\end{array}$ \\
\hline $\begin{array}{l}\text { Central nervous system, Glasgow } \\
\text { Coma Scale }\end{array}$ & 15 & $13-14$ & $10-12$ & $6-9$ & $<6$ \\
\hline $\begin{array}{l}\text { Renal, Creatinine, mg/dL. Urine } \\
\text { output, } \mathrm{mL} / \mathrm{d}\end{array}$ & $<1.2$ & $1.2-1.9$ & $2.0-3.4$ & $\begin{array}{l}3.5-4.9 \\
<500\end{array}$ & $\begin{array}{l}>5.0 \\
<200\end{array}$ \\
\hline
\end{tabular}

The severity of sepsis is correlated with the mortality rate. Around 18 millions new cases of sepsis are reported every year in the world with the mortality rate is around $30-50 \%{ }^{7}$. The incidence of sepsis has increased substantially in the past three decades, associated with an increasingly aging population, increased the use of immuno-suppressive drugs, and the growth of multiresistant bacterial infections. ${ }^{1}$ The recent data shows that 18 millions of sepsis occur annually with a mortality rate of $30 \%$ so that the early diagnosis in assessing the severity of sepsis is indispensable as a guide of an early and specific therapy. Clinical diagnosis of sepsis and the assessment of sepsis severity is quite complicated because of the presence of signs and symptoms that are not specific, and variant. ${ }^{4}$ Sepsis ranks third of the ten most diseases in the Dr. Soetomo Hospital Surabaya in 2014. The incidence of sepsis was 2446 cases in 2013 and 3060 cases in 2014. Most cases of sepsis were aged 45-64 years. Sepsis deaths were 1653 from 3060 cases (54\%) in 2014 and 1487 from 2446 cases (60.8\%) in 2013..$^{5}$

Procalcitonin (PCT) has been considered as a better biomarker of the systemic inflammatory response to infection. Procalcitonin has been widely used for the diagnosis of sepsis but not for the severity of sepsis. ${ }^{4}$ Procalcitonin is a calcitonin prohormone, the level increases when sepsis occurred and has been recognized as a marker of severe infectious diseases. ${ }^{1}$ Procalcitonin $>0.5 \mathrm{ng} / \mathrm{mL}$ are generally used as cut off values for the diagnosis of sepsis. However, $37.9 \%$ of patients with bacterial sepsis gave a PCT level of $<0.5 \mathrm{ng} / \mathrm{mL}^{7}$ Research conducted at Dankook University Hospital, South Korea, between December 2014 found PCT levels in healthy people: $<0.05 \mathrm{ng} / \mathrm{mL}$, local infection: $0.05-0.49 \mathrm{ng} / \mathrm{mL}$, sepsis: $0.5-1.99 \mathrm{ng} / \mathrm{mL}$, severe sepsis $2-9.99 \mathrm{ng} / \mathrm{mL}$ and septic shock > 10 $\mathrm{ng} / \mathrm{mL}^{6}$

This study aimed to analyze the correlation of procalcitonin level with sepsis severity based on SOFA score.

\section{METHODS}

This type of research was observational with a cross-sectional study design in septic patients. The research sample was whole blood (EDTA blood) from patients suspected of SIRS or sepsis in the Intensive Observation Room (ROI), Resuscitation Room (RES), and Intensive Care Unit (ICU) of Dr. Soetomo Hospital. The subjects fulfilled the criteria for sample acceptance, from December 2017 to February 2018. All subjects who participated in this study were willing to participate in the study by signing informed consent. Analyses were conducted to determine levels of PCT at research and development Department of Clinical Pathology, Dr. Soetomo Hospital. The sampling technique was consecutive sampling. Procalcitonin levels were quantitatively examined using Immuno-Chromatographic Test (ICT) method using the RAMP ${ }^{\circledR}$. The method followed the 
instruction on insert kits from Response Biomedical Corporation. RAMP $\AA$ Procalcitonin has the advantage of having a small sample volume $(75 \mu \mathrm{L})$, without centrifugation, and produce the results within 15 minutes so that help speeds up the diagnosis of sepsis. Another advantage of this instrument is that it was already equipped with all the necessary equipment to perform the tests such as pipettes, tips, buffers, and the cartridge. The method was was suitable to diagnose the sepsis patients who required rapid action. The $R A M P \AA$ procalcitonin device could measure PCT levels from 0.20-200 $\mathrm{ng} / \mathrm{mL}$. Procalcitonin levels above $200 \mathrm{ng} / \mathrm{mL}$ will be reported as $200 \mathrm{ng} / \mathrm{mL}$ and below $0.20 \mathrm{ng} / \mathrm{mL}$ will be reported as $0.20 \mathrm{ng} / \mathrm{mL}$.

All study samples were adult patients ( $\geq 18$ years) and met the criteria for sepsis screening based on qSOFA and SIRS. The sample exclusion criteria were patients with a history of liver abnormalities, kidney disorders, diabetes mellitus, hepatitis B, malignancy, HIV infection, and patients who were receiving immunosuppressant therapy.

The data were analyzed using SPSS version 21.0 with the Kolmogorov-Smirnov test to find out whether the data were normally distributed or not. Spearman correlation test was used if the data were not normally distributed. Ethical merit was obtained from the Ethics Committee of Dr. Soetomo Hospital Surabaya, with Ethical Clearance number 764/Panke.KKE/I/2018.

\section{RESULTS AND DISCUSSION}

The number of the research subjects was 78 samples that met the qSOFA criteria with six samples excluded because they did not have a complete laboratory examination. This research obtains the sepsis group of 37 (51.4\%) males and 35 (48.6\%) females. The age of patients in this study varied, the youngest age is 23 years, and the oldest is 77 years with an average age of 47.4 years. The sepsis group consists of 11 patients from ICU, 42 patients from ROI room, and 19 patients from RES. The characteristic data of the sample included gender, type of ward, age, systolic blood pressure, leukocyte count, and frequency of breath shown in Table 2.

This research showed the lowest PCT levels in sepsis patients was $0.2 \mathrm{ng} / \mathrm{mL}$, and the highest concentration was $200 \mathrm{ng} / \mathrm{mL}$ with a mean of $21.03 \mathrm{ng} / \mathrm{mL}$ and the deviation standard of 14.63 (Table 4). Procalcitonin levels are almost undetectable in healthy individuals and can increase above $100 \mathrm{ng} / \mathrm{mL}$ in patients with severe systemic infection manifestations. ${ }^{1}$

The Mean Arterial Pressure (MAP) and Glasgow Coma Scale (GCS) data were taken from the medical record obtained from the clinician's examination. The $\mathrm{PaO} 2 / \mathrm{FiO} 2$, thrombosis, bilirubin, serum keratin are secondary data which were resulted from the laboratory examination. The average and standard deviation of SOFA score parameter from this study subject respectively is presented in Table 3. SOFA score result varied with a minimum value was 0 , the maximal value was 16 , the average score was 6.47 , and the standard deviation is 3.61 (Table 4).

Spearman correlation statistical test showed a

Table 3. SOFA score parameters

\begin{tabular}{ll}
\hline Parameter & Mean ( \pm SD) \\
\hline $\mathrm{PaO}_{2} / \mathrm{FiO}_{2}$ & $447.70( \pm 223.42)$ \\
Platelets & $263.20( \pm 156.51)$ \\
Bilirubin & $3.39( \pm 5.40)$ \\
$\mathrm{MAP}$ & $76.63( \pm 10.16)$ \\
$\mathrm{GCS}$ & $11.57( \pm 3.34)$ \\
Creatinin & $4.48( \pm 5.45)$ \\
\hline
\end{tabular}

Table 2. Characteristics of research subjects

\begin{tabular}{|c|c|c|c|}
\hline Characteristics & $\mathbf{N}$ & $\%$ & Mean ( $\pm S D)$ \\
\hline The number of research subject & 72 & & \\
\hline Male & 37 & 51.4 & \\
\hline Female & 35 & 48.6 & \\
\hline \multicolumn{4}{|l|}{ Ward } \\
\hline ICU & 11 & 15.3 & \\
\hline ROI & 42 & 58.3 & \\
\hline RES & 18 & 26.4 & \\
\hline Age (yearold) & & & $47.4( \pm 14.02)$ \\
\hline Leukocyte count $\left(10^{3} / \mathrm{mm}^{3}\right)$ & & & $99( \pm 14.81)$ \\
\hline Systolic blood pressure (mmHg) & & & $18.2( \pm 10.52)$ \\
\hline Respiratory rate (x/minute) & & & $25( \pm 2.69)$ \\
\hline
\end{tabular}


Table 4. Minimun-maximum level and correlation of PCT levels with SOFA scores

\begin{tabular}{lclll}
\hline & Min-Max & Mean $( \pm \mathbf{S D})$ & P & R \\
\hline SOFA & $0-16$ & $6.47( \pm 3.61)$ & & 0.752 \\
PCT $(\mathrm{ng} / \mathrm{mL})$ & $0,2-200$ & $21.03( \pm 14.63)$ & $<0.0001^{*}$ & 0.75 \\
\hline
\end{tabular}

significant correlation between SOFA scores with PCT levels $(r=0.752$ and $p<0.0001)$, namely the higher the SOFA score (the more organ dysfunction), the higher the PCT level (Table 4). The results are shown in Figure 1.

The average of SOFA score obtained in this study was 6.47 , so the probability of mortality increased about $37 \%$. There was a very large variation in SOFA score in this study (range $0-16$, SD 3.61). A high SOFA score was strongly associated with mortality rates and can be used to assess the degree of organ dysfunction. The increasing of the SOFA score is associated with the $35 \%$ mortality rate in the hospital while any reduction in the SOFA score is associated with the $10 \%$ mortality. ${ }^{1}$

Ferreira et al. mentioned that the SOFA score $\geq 11$ had a mortality rate of $>90 \%$ and a decrease in this score in 48 hours associated with reduced mortality by $6 \%$. If the score is not changed or tended to increase, the mortality rate increased by $37 \%$ in the initial score $2-7$ and $60 \%$ if the initial score $8-11 .{ }^{1}$

The proportion between the sample of males and females in sepsis patients in this study, respectively were 37 (51.4\%) and 35 (48.6\%). Females had a lower incidence of sepsis than males. Sakr et al. reported that the prevalence of sepsis in males was more than females due to the increased levels of estradiol in females that improve immune function. Sakr et al. also mentioned that males had more inflammatory mediators (TNF-, IL-1, and IL-6) than females. ${ }^{8}$ The sepsis incidence data in the Dr. Soetomo Hospital in 2013 and 2014 also showed the proportion of sepsis prevalence in males was higher than females. Sepsis prevalence in the Dr. Soetomo Hospital by sex in 2013 was 1380 cases, while in females was 1320 cases. The prevalence of sepsis cases in 2014 was 2203 males cases and in 1815 females. The sepsis mortality rate in 2013 and 2014 in males was also higher compared to females in the Dr. Soetomo Hospital. ${ }^{5}$ Pietropaoli et al. stated in his research that the high incidence of sepsis in males was caused by estrogen that was a protective of inflammation mediator. ${ }^{9}$ Martin et al. reported that sepsis was more common in males with possible reasons that males were more often exposed to environmental conditions and stress. ${ }^{1}$
Based on age grouping, the age range of sepsis patients was between 23-77 years. The mean age of patients with sepsis in the study was 47.4 years with a median of 51 years. Most subjects were between 51-60 years old. The age of 45-64 years old also dominated data incidence of sepsis in the Dr. Soetomo Hospital in 2013-2014. It showed the incidence of sepsis is increasing at an older age. The incidence of sepsis has increased substantially in the past 3 years which is associated with an increase in the aging population, increased use of immunosuppressive drugs and the growth of multiresistant bacterial infections. ${ }^{1}$ The older age is more susceptible to infections and complications because of several conditions such as Immune system dysregulation, potential malnutrition, increased comorbidities, exposure to resistant pathogens in nursing homes, and increasing dependence on invasive medical devices. ${ }^{10}$ Artero et al. reported on the results of epidemiological studies of sepsis in Valencia, Spain, the highest cases of sepsis happened at the age of 60 years. Old age is an independent factor of sepsis. Old age can increase the risk of colonization of gram-negative bacteria, especially if accompanied by comorbid disease, conditions of malnutrition, endocrine disorders (such as hypoadrenalism, hypothyroidism, and hypogonadism), which can disrupt the body response to sepsis. Artero said that patients aged over 65 years had a risk of sepsis occurring 13 times higher than patients with younger age. ${ }^{11}$

The mean of leukocyte obtained from our study was 18.247 per $\mu \mathrm{L}$. This study showed that the 22 (30.5\%) patients with sepsis had the leukocytes < 12,000 per $\mathrm{mL}$ and 50 (69.5\%) patients had leukocytes $>12,000$ per $\mathrm{mL}$. The increasing of leukocytes, particularly neutrophils and macrophages, are needed to kill bacteria via phagocytosis. The increasing of leukocytes accompanied their immature granulocytes in sepsis. ${ }^{12}$

The average respiratory rate of sepsis patients in this study was 25 times/minute. The increasing of the respiratory rate that occurs in patients with sepsis is due to the increase of the respiratory center activation by inflammatory mediators or in response 
to metabolic acidosis. The mean systolic blood pressure obtained in sepsis patients in this study was $99 \mathrm{mmHg}$. There is interference with the endothelial layer due to proinflammatory cytokines, including increased leukocyte attachment, vasodilation, loss of endothelial defense function, and edema, resulting in a decrease in cardiac output which results in a decrease in systolic pressure. ${ }^{10}$

The lungs, cardiovascular, kidney, liver, hematological, and central nervous systems are the physiological parameters used to define organ dysfunction. Laboratory variables that include $\mathrm{PaO} 2$, platelet counts, creatinine levels, and bilirubin levels are needed to determine the presence of organ dysfunction assessed through the SOFA score. ${ }^{2}$ The results we obtained were following the description of organ dysfunction.

Procalcitonin has been widely used for the diagnosis of sepsis. ${ }^{1,4}$ Our results confirm several previous findings which showed that PCT levels as one of the most promising sepsis markers in critical patients procalcitonin was able to complement routine clinical signs and laboratory parameters that indicate the presence of severe infection during hospital admission. Several studies reported that PCT levels increased with increasing severity of the inflammatory response to infection. ${ }^{1,46,13}$ This increase occurs in various severe infections and inflammation. PCT levels are found to be low in healthy and found to be high in infected patients, and patients with inflammatory diseases. These conditions cause the release of pro-inflammatory mediators (eg, IL-1ß, IL-6, and TNF- $\alpha$ ) either by direct pathway (induced by lipopolysaccharide or microbial-released toxins) or cell-mediated response. Further proinflammatory mediators can stimulate monocytes and induces the expression of mRNA of calcitonin on non-neuroendocrine cells to release the PCT to the plasma so that the levels of procalcitonin increase. Thus PCT seems to help assess the severity of sepsis, and also can support in predicting the prognosis of sepsis. ${ }^{4}$

ICT procalcitonin method found 13 patients with PCT levels $0.20 \mathrm{ng} / \mathrm{mL}$. Low PCT levels could be caused by patients had received antibiotic therapy before, the sampling place was a referral hospital from various regions. Procalcitonin levels increase rapidly between 2-6 hours, and reach the peak in 6-24 hours during bacterial infection process.

Procalcitonin levels may not increase in severe viral infections or inflammatory reactions that are not contagious. ${ }^{13}$ Procalcitonin level $>0.5 \mathrm{ng} / \mathrm{mL}$ is generally used as a cut off for the diagnosis of sepsis, but $37.9 \%$ of patients with a diagnosis of bacterial sepsis have PCT level $<0.5 \mathrm{ng} / \mathrm{mL}$. Procalcitonin is not a gold standard in determining bacterial infections but is a marker that can help diagnosis, especially in systemic inflammatory conditions or shock, so that rapid PCT examination will help septic patients get treatment as early as possible.

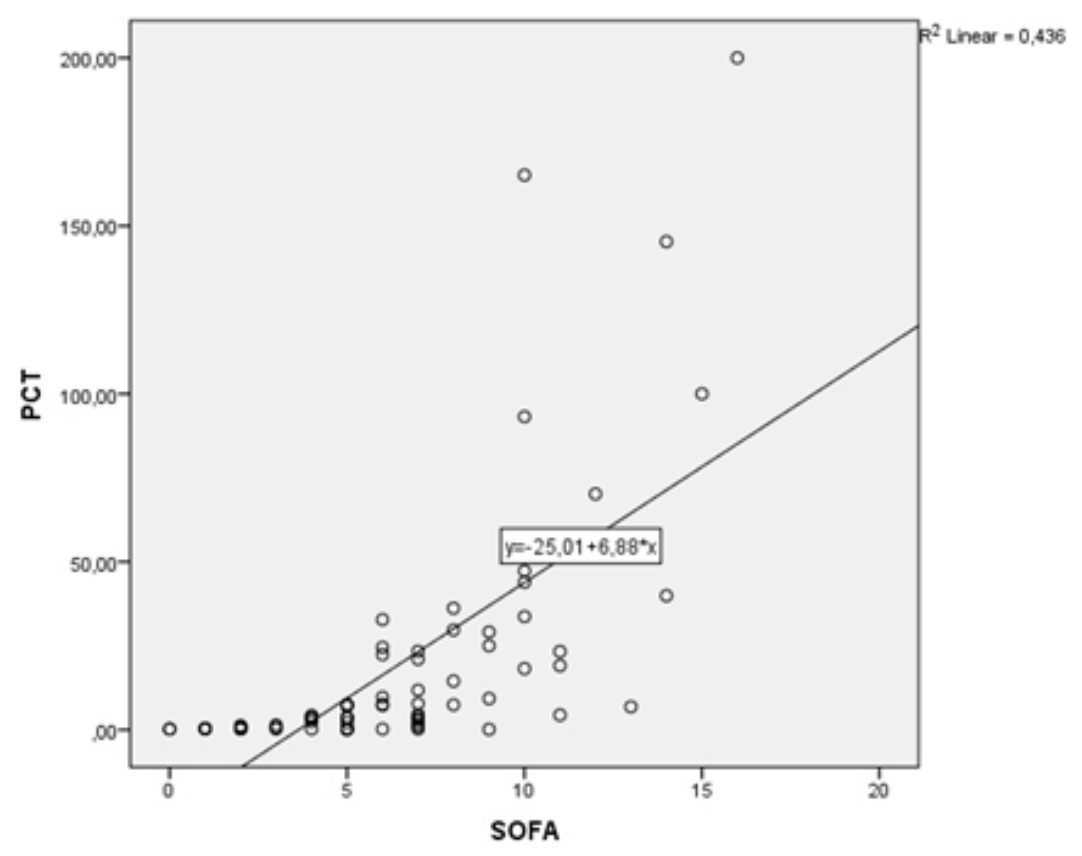

Figure 1. Correlation of procalcitonin levels with SOFA score $(r=0.752$ and $p<0.0001)$ 
Procalcitonin levels are related to the severity of multiple organ dysfunction syndromes (MODS) as assessed by SOFA score. ${ }^{1,4,13}$ This is consistent with the results of our study, which showed a significant correlation between PCT levels and SOFA scores with $p<0.0001$ and $r=0.752$ (Figure 1). Karlsson et al. reported that mortality in septic patients with severe sepsis was smaller in patients with PCT levels that decreased by more than $50 \%$ in the initial procalcitonin level. ${ }^{1}$ Research conducted by Annam et al. showed an increased SOFA score among patients with severe sepsis and septic shock $(p<0.001){ }^{4}$ This is similar to research conducted by Bale et al. and Moreno et al, there was, high mortality in septic shock group (83.3\%) followed by severe sepsis $(60 \%){ }^{4}$ Procalcitonin seem to help in assessing the severity of sepsis and can support by predicting the prognosis of sepsis. The increasing in SOFA scores reflects poor organ system function so that it can be a better predictor of mortality and also in assessing the severity of sepsis. ${ }^{1,4}$ Procalcitonin level and SOFA scores are strong predictors in determining prognosis according to the severity of sepsis. ${ }^{1}$

\section{CONCLUSION AND SUGGESTION}

This study concluded that there was a significant correlation between PCT level and SOFA score. Procalcitonin and SOFA score examination should be performed routinely in patients with sepsis so that the prognosis can be predicted, thus more quickly carried out an initial treatment to reduce mortality.

\section{REFERENCES}

1. de Azevedo JRA, Torres OJM, Beraldi RA, Ribas C, Malafaia O. Prognostic evaluation of severe sepsis and septic shock: Procalcitonin clearance vs. $\delta$ sequential organ failure assessment. J Crit Care, 2015; 30(1): 219.e9-219.e12. Available from: http://dx.doi.org/ 10.1016/j.jcrc.2014.08.018 [Accessed 12 May 2018]

2. Singer $M$, Deutschman CS, Seymour CW, Shankar-Hari $M$, Annane $D$, Bauer $M$, et al. The third international consensus definitions for sepsis and septic shock (sepsis-3). JAMA, 2016; 315(8): 801-10.

3. Marik PE, Taeb AM. SIRS, qSOFA and new sepsis definition. J Thorac Dis, 2017; 9(4): 943-5.

4. Annam V, Maleedhu P, Bhaskar MV, Venugopal L. Evaluation of serum procalcitonin levels and sequential organ failure assessment score in assessing the severity and outcome of sepsis. Int J Sci Study, 2016; 3(10): 48-51.

5. RSUD Dr. Soetomo. Sepsis Incidence Data 2014. Surabaya, 2015.

6. Joen JS, Ji SM. Diagnostic value of procalcitonin and CRP in critically ill patients admitted with suspected sepsis. J Dent Anesth Pain Med, 2015;15(3): 135-140. Available from: https://synapse.koreamed.org/ DOIx.php?id=10.17245/jdapm.2015.15.3.135 [Accessed 20 May 2018]

7. Vijayan AL, Vanimaya, Shilpa Ravindran, Lakshmi S, Kartik R, Manoj G. Procalcitonin: A promising diagnostic marker for sepsis and antibiotic therapy. 2017; 5(51): 1-7.

8. Sakr Y, Elia C, Mascia L, Barberis B, Cardellino S, et al. The influence of gender on the epidemiology of and outcome from severe sepsis. Critical Care, 2013; 17: R50.

9. Pietropaoli A, Glance L, Oakes D, Fisher S. Gender differences in mortality inpatient with severe sepsis and sepsis shock. Gend Med, 2010; 5(7):422-37.

10. Iskander KN, Osuchowski MF, Stearns-Kurosawa DJ, Kurosawa S, Stepien D, et al. Sepsis: Multiple abnormalities, heterogeneous responses, and evolving understanding. Physiol Rev, 2013; 93(3): 1247-1288.

11. Artero A, Zaragoza R, Nogueira JM. Epidemiology of severe sepsis and septic shock. Sev sepsis-septic shock. Underst a serious kill. 2012;3-25. Available from: http://www.intechopen.com/books/severesepsis-and-septic-shock-understanding-a-seriouskiller/epidemiology-of-severe-sepsis-and-septicshock [Accessed 2 June 2018]

12. Kurosawa S, Osuchowski MF, Valentine C, Remick DG. The pathogenesis of sepsis. Annu Rev Pathol, 2011; 6: 19-48.

13. Sudhir U, Venkatachalaiah RK, Kumar TA, Rao MY, Kempegowda P. Significance of serum procalcitonin in sepsis. Indian J Crit Care Med, 2011; 1(11): 1-5. 